\title{
Globalização e etnicização em Salvador
}

\author{
Manuela Borges Domingues \\ Doutora em Antropologia (Universidade Nova de Lisboa) \\ Pesquisadora do Instituto de Investigação Científica Tropical \\ Lisboa, Portugal \\ manuelaborgesdomingues@gmail.com
}

\begin{abstract}
Resumo N este texto propõe-se refletir sobre alguns aspectos do processo, presente e passado, de construção de uma identidade cultural afro-brasileira e dos seus laços com outros territórios e culturas, constituindo um meio de mobilização para a reivindicação da plena cidadania no plano transnacional. Ao longo da história, os negros brasileiros celebraram continuadamente a sua africanidade ou negritude, mas só recentemente os negros de Salvador puderam-no fazer abertamente. $M$ as nunca, como hoje, a globalização permitiu uma divulgação de significantes em nível planetário. Através da mídia ou pela internet, os interessados podem, independentemente do lugar geográfico a que pertencem, conhecer a cultura negro-africana e/ ou definir uma cultura da diáspora africana.
\end{abstract}

Palavras-chave globalização; etnicidade; associativismo; Salvador (B ahia).

$\mathrm{C}$ OM A "DESCOBERTA" DA ÁFRICA dá-se o encontro entre dois mundos, e 1492 é um ano-chave do processo de conhecimento mútuo entre todos os povos da Terra, marcando a primeira mundialização.

Pela primeira vez na história, todos os povos do planeta iriam, direta ou indiretamente, entrar em contato uns com os outros.

0 tráfico negreiro pelo Atlântico foi para a A mérica e a Á frica 0 efeito mais visível e com mais consequências dessa mundial ização.

$\mathrm{N}$ a A mérica, os países ligados comercialmente ao Atlântico receberam contingentes numerosos de escravos africanos que iriam influenciar a formação das sociedades americanas, mesmo se essa influência foi e é ainda ignorada frequentemente. $\mathrm{N}$ o entanto, ainda antes dos trabaIhos de R oger Bastide (Bastide, 1967), Gilberto Freyre contribuiu para o reconhecimento do protagonismo de africanos e seus descendentes através do livro M aîtres et esdaves (Freyre, 1974).

$\mathrm{N}$ a sociedade escravocrata, apesar dos interditos e preconceitos, sobreveio uma mestiçagem biológica sem precedentes. 0 utros africanos e afro-descendentes conseguiram sobreviver e manter a sua identidade em liberdade nos quilombos, e outros subsistiram através da preservação da sua cultura material, simbólica e espiritual.

A identidade cultural afro-brasileira resgatou a história dos afrobrasi leiros durante o regime escravocrata, na forma de uma cultura de resistência, representada pelos quilombos e pelas revoltas nas plantações e nas cidades, e da capoeira, desenvolvida pelos escravos, mas igualmente através das irmandades religiosas católicas de negros e mestiços, assim como através das religiões afro-brasileiras, e da música e da dança, ligadas aos rituais dessas religiões.

0 associativismo foi uma das formas privilegiadas de resistência desde a escravatura até a atual idade. No caso específico da Bahia, existiram irmandades, candomblés, juntas de alforria e cantos de trabal ho. 
0 candomblé é o nome dado ao modelo de religião afro-brasileira e designa grupos religiosos. As juntas de alforria eram associações de crédito mutualista destinadas a comprar a liberdade, os cantos de trabalho eram locais na rua onde se reuniam para comerciar, e as irmandades eram associações religiosas católicas de mestiços ou negros.

In Bahia, these imported African slaves developed mechanisms of solidarity, forged new identities, designed strategies of alliance, and established mechanisms for negociation among themselves and with other sectors of society as means of coping with slavery and oppressive conditions. (R eis, 2003, p. 240)

A lgumas dessas associações como as irmandades utilizaram o modelo de outras similares que já existiam em Portugal e na Europa católica, enquanto os candomblés e as juntas de alforria eram fundados em elementos africanos, mas de igual forma esse ativismo associativo é devedor da matriz africana, na qual 0 associativismo tem uma forte e longa tradição. "O que caracteriza o processo histórico negro-africano é o fato de notarmos uma linha de continuidade ininterrupta de determinados princípios e valores transcendentes que são capazes de engendrar e estruturar identidades e relações sociais" (Luz, 2000, p. 31).

A relevância das irmandades para os africanos e seus descendentes não se exaure no seu contributo para a compra de cartas de alforria, contribuindo para a libertação da escravidão, mas como espaços sociais onde se constituía e mantinha a solidariedade grupal e onde se elaborava a identidade e se preservavam memórias da herança africana (ver Luz, 2000, p. 343).

O Brasil atual foi moldado não só pela herança do colonialismo português, como pela histórica economia escravocrata.

No entanto, em numerosos países do continente americano, até uma data recente, mesmo os descendentes da diáspora africana ainda não haviam reconhecido, no quadro do processo de elaboração da identidade histórica nacional e étnica, o papel da África. A história da Á frica e dos descendentes dos africanos no Brasil estava ausente do ensino escolar e era ignorada pela sociedade em geral. A ssim, os afro-brasileiros achavam-se no processo de homogeneização, levando a uma cultura isenta de traços de matriz africana (como também acontece com a cultura indígena).

Paradoxalmente, o discurso oficial que mostrava o Brasil como um paraíso racial apresentou a mestiçagem como a panaceia igualitária para os novos cidadãos.

No século XIX, a abolição da escravatura foi apresentada como a panaceia para a igualdade antes negada. $N$ esse sentido, a mestiçagem foi aclamada como uma vitória dos direitos da cidadania e como acarreando a democratização. N o entanto, pelo contrário, essa ideologia do paraíso racial e da exaltação da mestiçagem contribuiu no Brasil, como noutros países, para o desconhecimento da diversidade e dos direitos relativos à identidade cultural dos descendentes da diáspora africana (D izidzienyo, 1971).

$N$ o século $X X$ elaborou-se a ideologia, por muitos considerada um mito, sem contrapartida na realidade factual, da democracia racial brasileira, que camuflou a real situação social na qual os afro-brasileiros são objeto de preconceitos raciais e ocupam os lugares mais baixos da estratificação social. "A broad it presents our country as a model of racial coexistence; internally, the myth is used to keep blacks tricked and docile" (N ascimento, 1999, p. 380).

Em reação a essa ideologia e por influência dos movimentos negros estrangeiros, será só nas últimas décadas do século XX que, na Bahia, se organizou 0 movimento negro, reivindicando a igualdade social a partir da sua diferença étnica. Esse movimento tem estado ativo na Bahia, nomeadamente em Salvador, que, segundo o censo de 2000, tinha uma população de 2.892.625 habitantes (ver IBGE C idades) e é também a cidade com maior população negra, só ultrapassada pela cidade de Lagos, na N igéria.

A história da formação da cidade de Salvador e da sua população relaciona-se com o tempo histórico em que esta era o centro político, social e econômico da colônia, onde dominavam as elites rurais sobre as classes trabal hadoras, reduzidas à escravatura. Ainda atualmente, $90 \%$ da sua população tem ascendentes negros, e a cultura afro-brasileira impregna a vida quotidiana, acompanhando o seu processo de modernização. A Bahia, no início do século XX, continuava a ser, essencialmente, um estado agrícola, com uma economia em declínio acentuado. A revitalização econômica iniciar-se-á com a industrial ização de Salvador, concretizada com a instalação da Petrobras e do polo petroquímico, implicando o surgimento de um setor tipicamente capital ista, e a expansão do mercado de trabalho, de que se beneficiaram, direta ou indiretamente, as populações mais pobres, predominantemente negro-mestiças, resultando na formação de uma classe média afro-brasileira. 0 ra, simultaneamente a essa nova ordem econômica e social, que propiciava ao segmento negro novas oportunidades de educação e emprego, elevando o nível de aspirações da sua juventude, ocorreu um amplo movimento cultural que, nos Estados U nidos e na Europa e daí para o Brasil, questionava os valores e as verdades da civilização ocidental, o conhecimento acadêmico, a superioridade dos modelos burgueses e dos seus valores éticos e estéticos, procurando alternativas noutras culturas, recuperando antigos e esquecidos valores e formas de expressão.

Conforme já foi referido, através da história os negros brasileiros celebraram continuadamente a sua africanidade ou negritude, mas só recentemente os negros de Salvador puderam fazê-lo abertamente. A 
identidade cultural afro-brasileira resgatou a história dos afro-brasileiros durante o regime escravocrata, na forma de uma cultura de resistência, representada pelos quilombos e pelas revoltas nas plantações e nas cidades, e da capoeira, desenvolvida pelos escravos, mas igualmente através das irmandades religiosas católicas de negros e mestiços, assim como na prática das religiões afro-brasileiras e através da culinária (com o uso do óleo de dendê, do gengibre, da malagueta, do quiabo, do inhame frito, das filhós de feijão, do "acarajé", entre outros al imentos e receitas de origem africana), assim como por meio da música e da dança ligados aos rituais das religiões afro-brasileiras e, ainda, pela continuidade das ligações com a Á frica.

$M$ as nunca, como hoje, a globalização permitiu uma divulgação de significantes em nível planetário. A través da mídia ou pela internet, os interessados podem, independentemente do lugar geográfico a que pertencem, conhecer a cultura negro-africana e/ ou definir uma cultura da diáspora africana. ${ }^{1}$ Ao mesmo tempo, o legado cultural do Atlântico negro tornou-se uma metalinguagem de protesto político contra situações opressivas diversas como mostra, por exemplo, a expansão do rap entre os descendentes de imigrantes marroquinos ou argelinos na periferia de Paris, ou a invenção do oriental hip hop ${ }^{2}$ pelos jovens turcos em Berlim que, autodenominando-se negros alemães, buscam cindir o ideal de pureza que orienta a construção da nacionalidade na A lemanha e impede a sua plena integração social.

H á uma relação direta entre a globalização e a etnicização do local (A gier, 2001, p. 16). A nova versão da Á frica no B rasil, em construção desde os anos 70 do século $X X$, recebe um fluxo de informações de origens bem diversas (socialização e memórias familiares, reportagens de televisão, revistas, livros, turismo cultural, "viagens", e coleta de informações e imagens na internet, entre outros). Por intermédio dos meios de comunicação globalizantes, a comunidade negra de Salvador teve oportunidade de conhecer o movimento negro dos Estados U nidos, através de militantes como A ngela D avis, M alcom X , M artin Luther K ing, 0 grupo Black Panthers, do Black Power, as gravações da
M otown, a linguagem do hip hop, ou os movimentos afro-caribanhos como o rastafarianismo, ${ }^{3}$ movimento que normal mente está associado ao reggae, ${ }^{4}$ que nasceu como música de intervenção social, divulgando a exploração dos afro- descendentes na "Babilônia", denominação que representa o sistema social construído através da escravização dos negros, da corrupção dos políticos, e de todas as injustiças praticadas no mundo, e apela à rejeição desse sistema, veiculando uma mensagem de esperança. 0 reggae e os penteados de cabeloslongos agrupados em canudos fortes, denominados dreadlocks, foram apropriados como símbolos do inconformismo e do empenho numa vida mais "natural" e justa, pelas comunidades de origem africana um pouco por todo o mundo, e também no Brasil.

D este modo, a elaboração, em Salvador, de uma cultura negra foi eminentemente transnacional e essencialmente construída através de uma bricolage de elementos heterogêneos, donde resultaram novas criações culturais, e caracterizou- se pela ação comunitária, numa perspectiva de apropriação de elementos culturais de origens diversas, para a construção de uma identidade negra afro-brasileira.

É no contexto transnacional que se insere 0 movimento cultural negro em Salvador, acionando processos conducentes à valorização social dos afrobrasileiros, ao usufruto pleno dos seus direitos cívicos e à integração dos afro- descendentes nas instituições da sociedade global. Essas aspirações, de mudanças no estatuto social dos negros e mestiços, e de redefinição da sua identidade social, traduziram-se no surgimento, na década de 1970, de um "movimento negro" que se reforçou nas décadas seguintes até hoje, cuja perspectiva é a plena integração dos afro - brasi lei ros na economia e na sociedade nacionais, a partir da valorização étnica, isto é, da redefinição da sua identidade social como negros.

Por conseguinte, essa procura identitária foi determinada pelo imperativo político de combater as estruturas que reproduzem as desigualdades raciais e foi animada, tanto a partir da "cultura afro-brasileira" quanto pelo legado cultural e político do "Atlântico negro", isto é, o movimento pelos direitos civis nos

10 termo diáspora deriva do verbo grego speiro (disseminar) e da preposição dia (para o outro lado de). Quando o termo era usado relativamente a pessoas, significava migração e colonização na Grécia antiga. A expressão "diáspora africana" surge nos textos a partir da segunda metade do século XX, por influência da cultura greco-judia, inspirada na experiência do exílio do povo judeu. Por este fato alguns autores preferem substituir o termo "diáspora" por outros, como "dispersão africana" (ver Prah, 1998, p. 72-73; Shepperson, 1982).

20 hip hop, considerado nos Estados Unidos um estilo musical autenticamente negro, utiliza elementos latino-americanos, caribenhos e norteamericanos.

3 Movimento social e religioso, sem dogmas nem chefes, surgido na Jamaica durante os anos 30 do século XX, baseado nas palavras de Marcus Garvey, um jamaicano que se tornou famoso como líder do movimento negro no início do século passado.

4 A origem do reggae está na música negra norte-americana, que era ouvida na Jamaica nos anos 40, e da sua mistura com o som local, 0 mento, dando inicialmente origem ao ska, que será a música da independência da Jamaica. Posteriormente, nos anos 60 , e com o surgimento de uma nova realidade social numa Jamaica soberana, o ska deu origem ao rock steady, que assumia uma finalidade de intervenção social, ainda hoje reconhecido em toda a música reggae. Com esse nome, o reggae surge apenas no final da década de 60, através de uma nova geração de músicos ligada ao movimento rastafári e orgulhosa das suas origens africanas. 
Estados U nidos e ainda pela "renascença cultural caribenha" (Guimarães, 2000, p. 28), assim como pelo discurso afro-centrista e pan-africanista que recorre à construção mitológica de um passado africano glorioso, tendo como arquétipo os antigosimpérios africanos e o Egito faraônico, e que teria sido interrompido pela colonização e negado pela historiografia ocidental.

Essa referência a uma África antiga poderosa já tinha precedentes: em 1899, o Clube U niformizado "Embaixada A fricana" desfilou no carnaval de Salvador com o tema do Egito. Essa estratégia de valorização dos povos africanos e do seu patrimônio cultural como símbolos positivos na comunidade negra em geral corresponde ao que hoje se chamaria de "ação afirmativa". I gualmente as referências à história do negro na diáspora africana integrava os temas dos clubes uniformizados negros no carnaval, que davam realce aos feitos de maior destaque na história da resistência e luta dos afro-descendentes ao regime escravocrata, como os quilombos, as revoltas negras, a personagem de Zumbi, ou as religiões afro-brasileiras, considerados como paradigmas de resistência às estruturas de dominação impostas pelos brancos. A inda no século XIX a construção da identidade cultural dos negros soteropolitanos procurou legitimar a sua igualdade de estado "civilizatório" com os brancos através da celebração de culturas florescentes na África, reconhecidas como adiantadas em progressos técnicos, como os mouros, egípcios e etíopes e de africanos heroicos na luta contra os europeus, como M enelik II, rei da Etiópia, que conquistou grandes vitórias nas lutas contra as tropas colonizadoras italianas e obteve a independência na batal ha de 1896 (R odrigues, 1995, p. 110, 115-118).

Este exemplo, de um clube uniformizado, segundo o modelo das elites brancas, constituído por negros que procuravam contrariar a imagem ocidental de uma África pobre, selvagem e sem "civilização", esclarece na medida em que os afro- descendentes tiveram de usar as mesmas armas do 0 cidente, isto é, pensar-se através das categorias ocidentais. Esse fenômeno de apropriação de significantes universalistas para construir significados particulares e locais foi objeto da tese de Jean-Loup A mselle (A mselle, 2001).

Para caracterizar esse movimento que marcou 0 cenário do "movimento negro" em Salvador, utilizouse 0 conceito de reafricanização da cultura afro-brasileira. N o entanto, a noção de reafricanização implica que os afro-brasileiros teriam perdido uma "cultura africana original" e essa perspectiva essencial ista e estática da cultura é redutora, ignorando o fenômeno da dinâmica da cultura africana e da sua reinterpretação na história afro-brasileira. Em alternativa à noção de reafricanização, para caracterizar as formas culturais contemporâneas afro-brasileiras em Salvador, é mais apropriado esclarecer as suas conexões e contextos, uma vez que a identidade é por natureza relacional, remetendo sempre para um "outro": outro lugar, outro tempo, outras pessoas. É a relação com o passado, com outras culturas, com outros lugares que contribui para um acervo de informações, que permitem uma contínua recriação da cultura que é reivindicada para definir a posição social da identidade negra em Salvador (A gier, 2001, p. 10, 14).

0 movimento negro na Bahia esteve sempre intimamente ligado às expressões culturais, essencialmente através da música, de inúmeras associações culturais ligadas aos blocos carnavalescos e, também, de afirmações identitárias e projetos educativos e profissional izantes dirigidos à comunidade afro-brasileira mais carente.

A inovação musical na Bahia, e a sua ampla difusão, nacional e internacional, através da indústria cultural e da mídia, criou uma nova economia do lazer, organizou-se de um modo empresarial, obedecendo a uma lógica mercadológica, visando alcançar o maior número de consumidores, e conquistou o mercado da indústria cultural no Brasil e também em outros países. D este modo, a expressão cultural, essencialmente através da música, permitiu dar visibilidade às condições, históricas e contemporâneas, dos afro-descendentes, retomando os mecanismos das tradições orais na preservação do passado, dando sentido ao presente e, por aí, criando aspirações quanto ao futuro.

Se o movimento negro em Salvador se afirmou principalmente no plano cultural, a mobilização dos afro-brasilei ros resultou da linguagem visual, gestual e rítmica compartilhada e da estética, história e cultura afro-brasileiras, revalorizando os elementos culturais de origem africana, e, no plano simbólico, da adesão às novas formas de expressão que se evidenciaram na participação carnavalesca.

E é pelo carnaval que tudo começou.

Em Salvador, até a década de 70 do século passado, o carnaval não constituía um tempo e um espaço de inversão e contestação dos valores e hierarquias sociais, mas, em 1975, os afro-descendentes chegaram, viram e conquistaram o carnaval soteropolitano.

Em 1975, quando os negros eram implicitamente, mesmo se não abertamente, excluídos dos blocos carnavalescos, um bloco negro, que ficaria conhecido pelo nome de llê Ayê (que pode ser traduzido como casa da vida), constituído por jovens do Bairro da Liberdade, desfilou no carnaval, dando visibilidade à comunidade afro-descendente, expondo publicamente a discriminação dos afro-descendentes, exibindo cantares, danças e fantasias de negros, afirmando que o negro era belo e forte, sedutor e atraente, inteligente e consciente.

Inspirado no movimento norte-americano Black Power, esse grupo denominou-se originariamente "Poder N egro", mas, como Ihes foi proibido o registro com esse nome, no primeiro ano desfilou sem nome, cantando "M undo negro". No ano seguinte, inspi- 
raram-se num documentário sobre o mundo animal exibido na televisão, apresentando-se vestidos como os dançarinos Watusi e, no terceiro ano, os refrões das canções foram cantados em iorubá, língua africana que se perpetuou no Brasil como língua litúrgica das religiões afro-brasileiras.

0 exemplo das temáticas e elementos escolhidos pelo Ilê Ayê, para afirmar uma identidade negra - o movimento negro norte-americano (Black Power), os guerreiros W atusi exibidos na televisão e a cultura afro-brasileira - , remete aos processos de reelaboração de uma africanidade, através de significantes planetários (A mselle, 2001).

A afirmação identitária do bloco negro ultrapassou a mera denúncia e o protesto contra a discriminação para assumir que o negro é belo e forte, inteligente e consciente. Essa afirmação da identidade negra teve êxito, uma vez que provocou reações hostis e indignadas da elite dominante. 0 jornal A Tarde, de 12 de fevereiro de 1975, publicou um editorial intitulado "Bloco racista - nota destonante", onde se afirmava:

Conduzindo cartazes onde se liam inscrições tais como: M undo N egro, Black Power, N egro para você, etc., o Bloco Ilê Aiyê, apelidado de Bloco do racismo, proporcionou um feio espectáculo este $C$ arnaval. A lém da imprópria exploração do tema e da imitação norte- americana, revelando enorme falta de imaginação, uma vez que em nosso país existe uma infinidade de motivos a serem explorados, os integrantes do Ilê A iyê, todos de cor, chegaram até à gozação dos brancos e demais pessoas que os observavam do palanque oficial. Pela própria proibição existente no país contra o racismo é de esperar que os integrantes do Ilê voltem de outra maneira no próximo ano, e usem em outra forma a natural liberação do instinto característica do Carnaval. (A Tarde, 1975).

0 êxito das suas afirmações identitárias pode ser visto pelas mudanças que desencadeou na forma como a comunidade negra era, ou, antes, não era, vista na sociedade global e ainda pela sua contribuição para a instituição de novas relações entre essa comunidade e a mídia.

$\mathrm{N}$ a sequência desses resultados, o Bloco Ilê Ayê conseguiu sensibilizar a população para a luta contra o racismo e conscientizar a comunidade negra da sua posição social inferior, discriminada e excluída, e, por aí, mobilizá-la para participar de eventos que promovessem a autoestima. Particularmente, incentivou a criação de escolas alternativas que possibilitassem 0 acesso à educação e à profissionalização dos afro-descendentes, criando oportunidades para a sua integração no mercado de trabalho, tradicionalmente dominado pelos brancos.

A Associação Cultural Bloco Carnavalesco Ilê Ayê tem já mais de trinta anos de existência e trabalha com a comunidade do Bairro da Liberdade, o maior bairro popular da cidade, onde predomina a população de baixa renda e negro-mestiça. A partir de 1995, o Ilê Ayê implantou o Projeto de Extensão Pedagógica, a Escola de M úsica e a Escola Profissionalizante, tendo como objetivo a educação preventiva contra a exclusão e a marginalização social dos membros da comunidade com que trabal ha.

A pedagogia adotada configura o ensino integrado de competências artísticas, profissionais e acadêmicas, numa perspectiva de conscientização étnica e cívica, dos jovens afro-descendentes oriundos de famílias carentes. ${ }^{5}$

Existem muitos outros grupos culturais organizados e funcionando à semelhança deste pioneiro, que não são aqui mencionados, por uma questão de economia, mas, também, para não deixar de referir um qualquer, pois são todos merecedores da nossa admiração pelo trabalho comunitário e em prol do fim da discriminação dos afro- descendentes. Foi efetivamente uma surpresa e uma inspiração descobrir a mobilização participativa dos cidadãos em luta por justiça e pelo pleno usufruto dos seus direitos de cidadania e, no caso particular dos afro-descendentes, a sua capacidade de utilizar a indústria cultural para denunciar o preconceito racial, redefinir a identidade brasileira como multicultural e trabal har para formar cidadãos conscientes e competentes para a nação brasileira.

N este contexto, as dinâmicas associativas foram e são ainda hoje parte importante do patrimônio cultural afro-brasileiro, compreendido como fenômeno social construído pelos sujeitos em situações de desigual dade social, e testemunham a dinâmica da relação entre os processos de global ização e etnicização.

$N$ esse sentido, o recurso ao discurso étnico por parte do movimento negro consubstancia uma estratégia de mobilização e reivindicação de uma mudança da sua identidade social estigmatizante no sistema de relações raciais baiano (ver M orales,1990).

5 Ver mais sobre as atividades dessa associação em Araújo (2002). 


\title{
Referências
}

AGIER , M ichel. Distúrbios identitários em tempo de globalização. M ana, v.7, n. 2, p. 7-33, 2001.

AM SELLE, Jean-Loup. Branchements. Anthropologie de I'U niversalité des C ultures. Paris: Flammarion, 2001.

A R AÚ J0, Zulu. A influência dos blocos afro na formulação e implementação das políticas afirmativas na cidade de Salvador. In: XIII ENCONTRO DA ASSOCIAÇÃO BR ASILEIRA DE ESTUDOS POPULACIONAIS. O uro Preto, M inas G erais, 4 a 8 de novembro 2002.

A TARDE. Bloco racista - nota destonante. Salvador, 12.2.1975. [Editorial].

BAST IDE, R oger. L es A mériques noires. Les civilisations africaines dans le N ouveau M onde. Paris: Payot, 1967.

DIZIDZIEN YO, A nani. T he position of blacks in Brazilian society. London: M inority $\mathrm{R}$ ight Groups, 1971.

FR EY R E, Gilberto. M aîtres et esdaves. La formation de la histoire de la societé brésilienne. Paris: G allimard, 1974.

GUIM AR ÃES, António. Prefácio. In: GUIM AR ÃES, A ntônio S. A.; HU N TLEY, Lynn (O rgs). T irando a máscara. Ensaiossobre o racismo no Brasil. São Paulo: Paz e Terra, 2000.

IBGE. Cidades. D isponível em: <http:// w w w.ibge.gov.br/ cidadesat/ topwindow.htm?1>. A cesso em: 30.10.2008.

LUZ, Aurélio. A gadá: dinâmica da civilização africano- brasileira. Salvador: Editora da U niversidade Federal da Bahia, 2000.

M OR A LES A na. E tnicidade e mobilização cultural em Salvador. Salvador, 1990. Dissertação (M estrado em C iências Sociais) - U niversidade Federal da Bahia.

NASCIMENTO, Abdias. The myth of racial democracy. In: LEVIN E, R obert M.; CR O CITTI, John J. (Eds.). $T$ he $B$ raz il reader. London: Latin A merica Bureau, 1999.

PR AH, Kwesi Kwaa. B eyond the color line: pan-A fricanist disputations. Selected sketches, letters, papers and reviews. A smara, Eritrea: A frica W orld Press, 1998.

R EIS, José J. Ethnic polities among A frican in N ineteenth-C entury Bahia. In: LOVEJOY, Paul; TR OTM AN, $D$ avid (O rgs). T rans- $A$ tlantic dimension of ethnicity in the A frican diaspora. London: C ontinuum, 2003.

RODR IGU ES FILHO, R aphael. A africanização do carnaval de Salvador, B A : a recriação do espaço carnavalesco (18761930). São Paulo, 1995. D issertação (M estrado em H istória) - Pontifícia U niversidade C atólica de São Paulo.

SH EPPER SON, George. African diaspora: concept and context. In: HAR R IS, Joseph (Ed.). G lobal dimensions of the A frican diaspora. Washington, DC: Howard U niversity Press, 1982.

\section{Globalization and Ethinicization in Salvador}

\begin{abstract}
The text builds on empirical data of «black» organizations focusing on logics, practices and strategies which transform living experiences of A fro-Brazilian groups by overcoming the economic precariousness, marginalization, social sub-alternization and symbolic violence of their everyday lives. The analysis of strategies and organizations of resistance and struggle for power developed by groups focuses on the cultural representations of black identity, past and present, including those which inform the construction of identities and contribute to their present social condition, as well those on which the black have historically based their strategies of resistance and transformative innovation.
\end{abstract}

Key words: globalization; ethnicity; associativism, Salvador (Bahia).

\section{Globalización y etnicización en Salvador}

\begin{abstract}
Resumen
Este texto propone reflejar sobre algunos aspectos del proceso, presente y pasado, de construcción de una identidad cultural afrobrasileña y de sus lazos con otros territorios y culturas, constituyendo un medio de movilización para la reivindicación de la plena ciudadanía en el plan transnacional. Por medio de la historia, los negros brasi leños celebraron continuadamente su africanidad o negritud, pero sólo recientemente los negros de Salvador lo pudieron hacer abiertamente. Sin embargo, nunca, como hoy, la globalización permitió una divulgación de significantes a nivel planetario. Por los medios de comunicación o por internet los interesados pueden, independientemente del lugar geográfico a que pertenecen, conocer la cultura negro- africana y/ o definir una cultura de la diáspora africana.
\end{abstract}

Palabras clave: globalización; etnicidad; asociativismo; Salvador (Bahia). 